\title{
Libertando-se de controles aversivos do passado para entrar em contato com contingências do presente: um estudo de caso
}

\author{
Camila Muchon de Melo \\ Universidade Federal de São Carlos \\ Maura Alves Nunes Gongora \\ Universidade Estadual de Londrina
}

\begin{abstract}
Resumo
Descreve-se a análise de um caso clínico com base na Análise do Comportamento e na filosofia behaviorista radical. Enfatiza-se mais a interpretação das queixas que os procedimentos implementados. Trata-se de uma cliente cuja queixa referia-se a comportamentos encobertos de sonhar e pensar obsessivamente em seu passado, principalmente naquilo que se relacionava a um antigo namorado. Além disso, apresentava dificuldades nas relações familiares e diagnóstico médico de depressiva. A queixa quanto aos sonhos e pensamentos foi interpretada como produto de contingências aversivas às quais foi exposta quando jovem e esquiva de suas atuais relações familiares insatisfatórias. Descrevem-se, ainda, outras interpretações, os procedimentos delas derivados e o modo como, no processo terapêutico, superar as dificuldades com o passado possibilitou à cliente enfrentar os problemas familiares atuais. Relata-se também como foi interpretado o controle comportamental exercido pelo diagnóstico médico e os procedimentos que permitiram a redução gradual da medicação antidepressiva. Procura-se demonstrar como as interpretações baseadas no behaviorismo radical levaram à aplicação de procedimentos que resultaram em maior contato da cliente com as contingências atuais e construção de novos repertórios interpessoais. Isto proporcionou-lhe maior autonomia e novas perspectivas para o futuro.

Palavras-chave: behaviorismo radical; interpretação; procedimentos clínicos.
\end{abstract}

\begin{abstract}
Getting free from aversive controls from the past to get in touch with contingencies of the present: a case study

The analysis of a clinic case is described based on behavioral analysis and on radical behaviorist philosophy. An interpretation of complaints is emphasized more than implemented procedures. The case, referred to here, is of a client whose complaint related to covert behavior of dreaming and thinking obsessively on her past, especially of what was related to an old boyfriend. Besides that, she had difficulties in family relations and had been diagnosed as being in a state of depression. Her complaint about dreams and thoughts was interpreted as product of aversive contingencies which she had been exposed to when a child and her attempts to avoid unsatisfactory family relations. Besides that, the present text describes other interpretations, the procedures that emanated from them and, in the course of therapeutic process, the way the overcoming difficulties with her past which made possible the ability of the client to face family problems. Also related is how the control of medical diagnosis over behavior was interpreted and the procedures which allowed gradual reduction of antidepressive medication. It is intended to demonstrate how the interpretations, based on radical behaviorism, permitted application of procedures which resulted in more contact of the client with actual contingencies and construction of a new interpersonal repertoire that provided her with more autonomy and new perspectives for the future.
\end{abstract}

Keywords: radical behaviorism; interpretation; clinic procedures.

Este artigo relata alguns segmentos de uma análise e intervenção clínica realizada com uma cliente apresentando comportamentos perturbadores de sonhar e pensar, entre outras dificuldades relacionadas com seu passado. Além de fundamentar-se nos princípios básicos da análise do comportamento, procurou-se nortear a análise pela filosofia behaviorista radical. No entendimento das autoras, o relato deste caso é particularmente relevante por demonstrar as possibilidades de se realizar análise comportamental de problemas complexos, bem como demostrar peculiaridades na evolução do processo terapêutico. Pretende-se destacar mais as análises dos problemas clínicos e do processo terapêutico que os procedimentos implementados. 
A cliente aqui referida, ao iniciar a terapia, encontrava-se com 40 anos e vivia com o marido e seu único filho de 20 anos. Estava casada há 20 anos; o marido era pedreiro, mas encontrava-se desempregado. $\mathrm{O}$ fillho tinha primeiro grau incompleto e não estudava e nem trabalhava. A cliente, com $1^{\circ}$ grau incompleto de escolaridade, trabalhava em comércio informal, vendia alimentos em domicílio, cuja renda era a única fonte de sustento da família. Foi encaminhada à clínica-escola de Psicologia por um psiquiatra do hospital universitário onde se submetia, há seis anos, a tratamento para depressão. Esse tratamento consistia em encontros de grupos de apoio semestrais e manutenção de medicação antidepressiva. Havia uma grande rotatividade de médicos residentes que a atendiam, sendo apenas o último a encaminhá-la para a psicoterapia, sugerindo-lhe, com este tratamento, a possibilidade de a cliente vir a ser dispensada da medicação antidepressiva. De início, queixava-se de comportamentos frequientes $\mathrm{e}$ perturbadores de pensar, sentir e sonhar, relacionados com um período de seu passado. Os sonhos e pensamentos "obsessivos" com o passado referiam-se a um período anterior ao seu casamento (quando tinha aproximadamente 16 anos) com destaque especial para um rapaz por quem fora apaixonada. Ela dizia ter flertado com o rapaz sem nunca ter chegado a namorá-lo e por isso supunha que o rapaz desconhecia os sentimentos que ela possuía em relação a ele. Afirmava não ter se aproximado e nem se casado com o mesmo por vergonha de contar-lhe que, provavelmente, não era virgem (uma suspeita decorrente de um encontro com um primo, na infância, confusamente descrito como estupro). Em decorrência do medo e da vergonha, caso esse fato viesse a ser descoberto, acabou se casando com o atual marido, uma vez que este não residia em sua cidade e poderia levá-la para longe do julgamento das pessoas ali residentes.

Afirmava, ainda, que sua educação fora muito rígida, e seu pai muito "machista". Quando criança, viveu em um meio muito simples, onde todas as amigas de sua mãe e as pessoas com as quais convivia, em geral, apresentavam preconceito explícito por meninas que não eram mais virgens. Frente a suspeita, nunca confirmada, de também não ser virgem, sentia-se, na época, extremamente ansiosa. Essa ansiedade continuava intensa, sempre que pensava ou sonhava em relação àqueles fatos do passado, constituindo para ela comportamentos muito aversivos dos quais queria se livrar. Nunca havia tratado do assunto com alguém e sentia-se "anormal" e "diferente" das outras pessoas. Apresentava muitas dúvidas sobre sexualidade, tema que lhe era importante, uma vez que seus problemas, no passado, referiam-se em grande parte à virgindade e à desinformação sobre esse assunto.

Afirmava que sua vida deveria ter sido diferente, culpando-se freqüentemente pelos atos cometidos no passado. Achava que poderia ter agido de outra forma com o rapaz por quem fora apaixonada, que poderia ter tentado descobrir se era virgem ou não, ter correspondido aos seus "flertes" e se casado com ele.
Nas primeiras sessões, toda vez que a terapeuta a questionava sobre aspectos de sua vida atual, a cliente se desviava para relatos de problemas anteriores, daquele seu passado. Mesmo assim, com a insistência da terapeuta, relatou muita insatisfação com a sua atual vida conjugal, sexual e familiar. Dizia-se muito arrependida de ter se casado com o atual marido, descrevendo-o como mal-humorado, calado e despreocupado com os problemas financeiros; mantinha relações sexuais com o mesmo apenas para evitar seu mau humor. Dizia que seu filho também era bastante calado e em algumas situações muito agressivo. Qualificava as interações familiares como muito ruins, tanto com o marido quanto com o filho. Em geral, justificava seus atuais problemas conjugais e familiares como sendo decorrência de ter errado no passado ao se casar com o atual marido e não com o antigo flerte.

Frente a situações adversas a cliente apresentava, na maioria das vezes, comportamentos de desespero. Um exemplo comum ocorria quando chovia e ela não podia sair com sua moto (na época seu único meio de locomoção) para trabalhar; relatava ficar desesperada e não conseguir usar aquele tempo para outras atividades, prestando atenção em tempo integral ao término da chuva. Era comum atribuir esses e outros comportamentos problema ao fato de "ter depressão", um diagnóstico recebido dos médicos e do qual ela quase não tinha informações.

Resumindo: constatou-se nas primeiras sessões que a cliente apresentava ao menos três possíveis problemas clínicos: o "pensar e sonhar obsessivamente com o passado além de comportar-se sob o controle de regras disfuncionais sobre o passado", "dificuldades nas relações familiares" e "depressão". Entretanto, sua queixa inicial resumia-se ao primeiro; queria livrar-se dos sonhos e dos pensamentos que a atormentavam. Seguem-se as análises, procedimentos e resultados relativos a cada um desses possíveis problemas clínicos.

\section{PENSAR E SONHAR OBSESSIVAMENTE COM O PASSADO}

O comportamento de sonhar muitas vezes é descrito pela comunidade verbal como algo "estranho", e as explicações dadas para "o que" sonhamos derivam-se, na maioria das vezes, de explicações místicas como premonições ou interpretações simbólicas. De acordo com o behaviorismo radical, o sonho, embora se constitua em comportamento encoberto, está sujeito às mesmas leis que governam os demais comportamentos, aqueles cujas ocorrências são públicas (comportamentos abertos).

O sonho faz parte do repertório do indivíduo, devido às contingências de reforçamento às quais responde no momento; bem como das contingências que o modelaram durante sua história de vida. Na prática isto equivale dizer que cada interpretação de sonho só pode ser feita para aquele cliente particular, de acordo com o seu contexto de vida... (Guilhardi, 1998, p. 263). 
Compreendendo quais contingências modelam e quais mantêm determinados sonhos, pode-se chegar a generalizações sobre uma classe mais ampla de comportamentos na qual estes se incluem. Neste estudo hipotetizou-se que tanto os sonhos perturbadores da cliente, quanto o pensar e o falar obsessivamente (em sessão) sobre aqueles temas do passado constituíam uma mesma classe comportamental. Dito em outras palavras, tinham a mesma função, embora sonhos e pensamentos constituíssem instâncias de comportamento encoberto (privado) e o falar em sessão se apresentasse como uma instância de comportamento aberto (público). A cliente não era punida ao sonhar e ao pensar no passado, ocorrendo a mesma condição ao poder falar abertamente em sessão, sobre seu passado; a esquiva de punição só parecia possível à cliente nessas condições de privacidade.

Contingências punitivas sistemáticas podem inibir partes importantes do repertório de uma pessoa, a qual passa a não apresentar publicamente as respostas punidas, no entanto, essas respostas podem continuar com sua força, apresentando-se em instâncias privadas (Skinner, 1998). Os temas referentes ao seu passado, no entender da cliente, eram altamente censuráveis, provavelmente por isso, apresentavam-se exatamente em condições nas quais não havia risco de ser punida por sua comunidade verbal, ou seja, nos sonhos, nos pensamentos e na psicoterapia.

O pensar, compreendido como fala encoberta, é interpretado por Skinner (1957) da mesma maneira com a qual interpreta a fala em geral, na forma aberta. Ambos (pensar e falar) são vistos como comportamento verbal operante, e como tal, modelado, mantido e modificado sob o controle de arranjos específicos de contingências próprias de cada comunidade verbal. A diferença na análise do falar e do pensar encontra-se na identificação das variáveis responsáveis pelo recolhimento ou não da fala para a forma oculta. Ainda, segundo o autor, um dos principais motivos para que certas falas (temas) permaneçam na forma encoberta, é, justamente, a ameaça de punição pela comunidade verbal.

\subsection{Procedimento}

Possibilitou-se à cliente falar sem censura sobre seu passado, podendo suscitar questões à terapeuta sobre todas as suas dúvidas. Desta forma, as respostas perturbadoras (sonhar e pensar sobre o passado) que antes se apresentavam apenas na condição privada puderam ser apresentadas também na forma pública (falar em sessão), ou seja, a terapeuta passou a fazer parte de sua comunidade verbal como uma audiência não punitiva. Esperava-se que, ao tornar menos aversivo o falar em sessão sobre o passado, este comportamento diminuísse em frequiência, ocorrendo o mesmo com os demais da mesma classe (sonhar e pensar).

\section{REGRAS DISFUNCIONAIS EM RELAÇÃO AO PASSADO}

Entendeu-se que a cliente se encontrava sob o controle de algumas regras disfuncionais em relação ao passado, as quais poderiam ser assim formuladas: "Meu passado poderia ter sido diferente"; "minha vida atual está muito ruim devido aos meus erros no passado"; "devido ao meu passado, sou diferente das outras pessoas (sou anormal)".

Para Skinner $(1969 ;$ 1974), o seguir regras e mesmo formular regras pode ser adaptativo, e contribui para o processo de aprendizagem do indivíduo, todavia, a formulação e o seguimento de regras podem isolar o indivíduo das conseqüências diretas de seu comportamento, aumentando a probabilidade de este apresentar dificuldades em relacionamento social, incapacidade para adaptar-se a situações novas e outros comportamentos considerados "não adaptativos". Catania (1999) afirma que, geralmente assumimos, que o comportamento de seguir regras é benéfico, mas nos casos em que as conseqüências por seguir regras sobrepõem as conseqüências das contingências o resultado pode não ser bom. Além disso, sugere que seguir regras é um processo verbal complexo, que maximiza o controle da comunidade verbal sobre seus membros.

Ainda, Skinner (1957) afirma que, ao pensar, a pessoa fala consigo mesma como se fosse uma comunidade verbal, entretanto, se decorrer muito tempo sem que a pessoa trate do referido assunto com a comunidade verbal pública, como forma de reabastecimento, sua fala encoberta (seu pensamento) pode tornar-se idiossincrático. Hipotetizou-se que seguir aquelas regras dificultava à cliente entrar em contato com certas contingências atuais, próprias de sua atual comunidade verbal.

Levantou-se também a hipótese de que a falta de informações sobre comportamento humano $\mathrm{e}$ sexualidade bem como a não-discriminação dos mantenedores de seus comportamentos-problema, contribuíram para que a cliente formulasse a regra de que o "seu passado poderia ter sido diferente" o que permitiu a manutenção dos comportamentos "perturbadores" no presente. Ao seguir essa regra, ela justificava seus problemas atuais com seu marido e com seu filho, interpretando-os como decorrentes do fato de não ter agido de outra maneira em seu passado. Resultado: a cliente não discriminava e não entrava em contato com as contingências atuais controladoras de suas relações familiares aversivas.

$\mathrm{O}$ fato de a cliente nunca ter conversado com alguém sobre esses problemas, isolando-a de certa forma da sua comunidade verbal, além de ter contribuído para a formulação da regra anterior (seu passado poderia ter sido diferente) parece, ainda, ter propiciado a formulação das outras regras: a de que "seria diferente das demais pessoas ou anormal" e a de que "se tivesse agido de forma diferente em seu passado o presente também seria diferente".

\subsection{Procedimento}


Ao lado da ênfase em uma interação empática da terapeuta com a cliente, já citada no procedimento anterior, em relação às regras acima, foram adotadas duas linhas gerais de procedimentos. Em uma primeira linha, procurou-se indicar à cliente uma visão de que tudo o que se passou com ela era "normal", no sentido de ser esperado ou natural, tendo em vista as circunstâncias nas quais tudo ocorreu. Conforme a cliente ia relatando seus problemas e os fatos do passado, a terapeuta ia sinalizando-lhe como os eventos avaliados por ela como "anormais" eram naturais e que em tais condições suas atitudes eram as respostas possíveis nas situações específicas daquele contexto, com o repertório comportamental decorrente de sua história particular.

Ainda na primeira linha de procedimentos, adotaram-se várias estratégias as quais possibilitaram à cliente observar como as outras pessoas (incluindo a terapeuta) falavam, lembravam, sonhavam e lidavam com suas histórias passadas. Esperava-se, desse modo, que ela passasse a ver-se como pessoa normal, e, além disso, tivesse modelos de como lidar mais apropriadamente com o passado, retirando desse o caráter censurável que a perturbava.

Outra linha de procedimentos levou em consideração a simplicidade e desinformação da cliente. A terapeuta forneceu-lhe diversas instruções e informações, sobretudo em sexualidade humana, esclarecendo muitas de suas dúvidas, visando diminuir o seu isolamento da sua comunidade verbal, isolamento do qual parecia decorrerem suas idéias fantasiosas e ao mesmo tempo aversivas sobre sexualidade.

\section{Resultados relativos aos problemas com o passado (itens 1 e 2)}

Após a $9^{\mathrm{a}}$ sessão, diminuiu sensivelmente a frequiência do sonhar, seguido do pensar e do falar, em sessão, sobre os problemas do passado. Ao final de 10 sessões a cliente não abordou mais o assunto espontaneamente, apenas se solicitada a fazê-lo. Além disso, quando solicitada, tratava do passado com tranquiilidade e facilmente voltava-se para o presente. A cliente passou a trazer para a sessão os assuntos referentes a problemas familiares atuais de forma espontânea, ou seja, possivelmente ocorreu uma mudança no controle de estímulos do passado para o presente. Se antes ela justificava seus problemas familiares como sendo função dos seus atos no passado, agora ela começava a se deter nas suas interações familiares para entender e solucionar parte de seus problemas atuais.

Afirmava, claramente, não se lembrar mais do antigo flerte e quando isto ocorria ou quando eventualmente sonhava com ele, era para ela um fato "normal", não perturbador, semelhante à lembrança de qualquer outro fato do seu passado. Com esses resultados foi possível, então, avançar para uma segunda fase do processo terapêutico, com enfoque sobre o presente.

\section{PROBLEMAS RELATIVOS ÀS RELAÇÕES FAMILIARES}

Segundo Keefe, Kopel e Gordon (1980), trocas afetivas fazem parte de uma classe de comportamento observada em uma relação conjugal; incluem-se nesta categoria comportamentos que vão desde a intimidade física ou trocas sexuais até presentes para o cônjuge ou trocas de afirmações verbais positivas de prazer, agradecimento ou cumprimento. Os autores afirmam que casais em conflito apresentam índices relativamente mais baixos de trocas afetivas quando comparados com casais que não apresentam problemas. Além disso, os primeiros apresentam altos índices de trocas negativas, o que pode ocorrer por dificuldades em habilidades interpessoais por parte de um ou de ambos os parceiros.

Em suas interações conjugais, constatou-se que a cliente apresentava índices muito baixos de trocas afetivas e dificuldades em relacionamento interpessoal, dificuldades estas também apresentadas por seu cônjuge. Um exemplo é que raríssimas vezes a cliente consequienciava de maneira positiva os comportamentos do marido de tentar agradá-la, ela sempre ficava mais sob o controle de aspectos negativos do comportamento dele em detrimento dos aspectos positivos. Ao relatar suas críticas ao marido, ela demonstrava esperar dele comportamentos próprios dos personagens românticos das novelas, às quais assistia exaustivamente. Como seu marido não apresentava aquelas características, em geral, o comportamento dele exercia sobre ela um controle aversivo ao qual ela respondia, freqüentemente, de forma agressiva ou com irritação.

A cliente apresentava semelhante padrão de trocas negativas nas interações com seu filho; interagia com ambos de modo controlador e coercitivo. Uma vez que a cliente, nesse momento da terapia (após a décima sessão) estava entrando mais em contato com as suas atuais contingências de vida, pareceu quase óbvia a hipótese de que ela poderia se beneficiar de procedimentos que a levassem a melhorar a qualidade das suas relações familiares. Em um modelo operante de análise das relações familiares cabe a hipótese de que seria possível e eficaz a cliente vir a discriminar o efeito de seu comportamento sobre o comportamento de seus familiares, e após isso, ser modelada a discriminar e conseqüenciar positivamente pequenas instâncias de comportamentos desejáveis tanto do filho quanto do marido, em um processo que a auxiliaria, ainda, a discriminar também os controles antecedentes e conseqüentes de seu próprio comportamento; em outros termos: produziria autoconhecimento.

Outra suposição era de que comportamentos da cliente de desespero quando algo a impedia de trabalhar ocorriam tanto em função de não poder se esquivar das relações familiares que se lhe apresentavam aversivas, quanto em função de ser o seu trabalho a única fonte de renda familiar, tendo a maioria das responsabilidades econômicas e domésticas sob seus cuidados. 


\subsection{Procedimento}

A cliente foi modelada a discriminar aspectos do comportamento do marido que lhe eram positivos, sempre analisando antecipadamente quais atitudes poderiam ser esperadas dele, ou seja, alterando seus comportamentos disfuncionais de esperar do marido ações semelhantes às dos personagens românticos das novelas.

Levantaram-se com a cliente alternativas mais eficazes de se comportar nas interações familiares (melhorar a comunicação em geral), ensinando-a como conseqüenciar de maneira positiva comportamentos do filho e do marido, e como lidar com questões que lhes eram aversivas. Por exemplo, maneiras mais adequadas de falar ao filho sobre comportamentos do mesmo que não a agradavam, maneiras diferentes das a que estava habituada, tais como gritar e xingar.

Outros procedimentos propiciaram melhoras em autoconhecimento. Por exemplo, a cliente foi levada a identificar quando exercia controle aversivo sobre as pessoas (filho, marido e parentes), e a identificar contingências que controlavam seus sentimentos de raiva e comportamentos explosivos ou até mesmo agressivos.

Avanços em autoconhecimento permitiram implementar estratégias para que a cliente lidasse mais adequadamente com as situações aversivas, entre elas, as de frustração; ou seja, em vez de comportamentos explosivos ou agressivos, descobrir e experimentar outros comportamentos socialmente mais eficazes e apropriados. Por exemplo, a partir do momento em que ela discriminou que seu desespero quando não podia trabalhar era, em grande parte, função de ser ela a única fonte de renda na família, foi possível levantar alternativas de como dividir as tarefas e responsabilidades econômicas com o filho e com o marido.

\section{Resultados (item 3)}

No início do procedimento no qual a terapeuta mostrava à cliente que se ela se comportasse de maneira diferente com seu marido e com seu filho as relações familiares poderiam mudar para melhor, a cliente parecia não compreender e nem acreditar. Somente depois de muitas demonstrações minuciosas e detalhadas pela terapeuta é que a cliente passou a experimentar pequenas mudanças no modo de agir com seu filho e então pôde verificar sinais de melhora nas interações com ele. A cliente deixa de se comportar de um modo problemático para se comportar de forma mais efetiva. Contudo, esse processo foi lento porque ela apresentava muitas dificuldades interpessoais a serem substituídas por comportamentos mais apropriados.

O processo de mudança iniciou-se com o filho e depois estendeu-se também ao marido e, eventualmente, com alguns parentes. $\mathrm{Na}$ medida em que as mudanças apareceram, a cliente passou a observar mais como se davam suas interações e a trazer exemplos e pedir orientações para a terapeuta.
Passou a exigir menos do marido, reconhecendo nele uma pessoa simples e calada, e dentro desses limites, aumentou também com ele as trocas positivas.

Em relação à distribuição das tarefas e responsabilidades domésticas e econômicas, no início, a cliente relatava já ter tentado de tudo para provocar mudanças nos comportamentos do filho e do marido; a terapeuta mostrou-lhe que seu marido e seu filho tinham se acomodado porque nada lhes faltava (alimentação, luz, água etc.), ela deveria encontrar uma alternativa para que eles se comportassem frente a esta situação de maneira mais cooperativa. A cliente passou a discriminar o que fazia para que todos dependessem dela. Seu marido tinha como procurar novos tipos de trabalho, mas não precisava uma vez que ela fazia tudo, então a terapeuta mostrou-lhe as consequiências benéficas para ela se as responsabilidades fossem redistribuídas.

Próximo à $25^{\mathrm{a}}$ sessão a cliente sofreu um acidente, quebrou a perna e ficou cerca de 60 dias com uma perna engessada. Disto decorreram mudanças drásticas nas contingências de vida da cliente as quais propiciaram mudanças comportamentais em todos os membros da família.

No início desse período, a cliente apresentou seu padrão comportamental de desesperar-se frente a uma situação adversa; quando sofreu o acidente relatou pensar obsessivamente em seu trabalho, voltando a trabalhar dois dias depois do acidente mesmo com o gesso e com a indicação médica de repouso absoluto. Porém, tal fato propiciou que tanto o marido quanto o filho se preocupassem com o trabalho da cliente, passando ambos a substituí-la na distribuição dos alimentos para não perderem a clientela. A cliente reforçou positivamente a iniciativa de ambos. $\mathrm{O}$ filho gostou do serviço e posteriormente, após a melhora da mãe, passou a trabalhar sozinho também entregando alimentos em outra região e contribuindo com as despesas da casa; o marido continuou ajudando-a em seu trabalho. Desta forma, mudanças acidentais nas contingências de vida da cliente aceleraram o processo terapêutico. O "aproveitamento" da oportunidade foi, provavelmente, maximizado pela cliente em função das orientações anteriormente recebidas da terapeuta.

Já no processo de alta a cliente utilizou-se de uma metáfora para descrever as mudanças ocorridas na sua vida:

\begin{abstract}
...uma família que ninguém fazia nada tinha uma vaquinha que produzia leite, e todos na família dependiam do leite da vaca; um dia São Pedro mandou um raio matar a vaca e aí todos foram trabalhar para sustentar a família.
\end{abstract}

\section{DEPRESSÃO}

Examinando-se os procedimentos implementados, já descritos, pode-se constatar que a terapeuta não atuou sob o controle do "diagnóstico de depressão", motivo pelo qual a cliente havia sido encaminhada para terapia. Ao contrário, analisou e procurou intervir 
nos comportamentos -problema, descritos pela cliente, visando construir um repertório comportamental apropriado e eficaz. Caso houvesse identificado comportamentos depressivos (aqueles considerados para o "diagnóstico de depressão"), os teria tratado da mesma forma. Aliás, ela identificou alguns e os tratou sem a preocupação (proposital) de vinculá-los ao rótulo de depressão; entre eles destacam-se os comportamentos queixosos e de irritação. Verificou-se que a cliente apresentava poucos dos comportamentos mais comuns da síndrome depressiva, por exemplo, não apresentava sentimentos de tristeza, desânimo e isolamento social (tinha uma vida ativa, gostava de seu trabalho e de fazer visitas, conversava muito com suas clientes e com os parentes que visitava, demonstrando prazer nessas atividades).

A esta altura poder-se-ia considerar resolvido o problema clínico - depressão - uma vez que os comportamentos depressivos identificados foram tratados junto aos demais. Entretanto, resta analisar ainda outra dimensão desse problema: a cliente se autodenominava portadora de depressão, entendendoa como doença crônica, e ingeria medicação antidepressiva.

Para Ullmman e Krasner (1975), não basta tratar dos comportamentos classificados nos diagnósticos médicos, é preciso analisar quem os classificou e porque o fez. Além disso, é preciso verificar se o "rótulo" [funcionando como uma regra] contribui para a manutenção dos problemas clínicos. Neste caso, a cliente justificava muito de seus problemas pelo fato de "ter depressão".

\subsection{Procedimento}

A cliente foi informada acerca do diagnóstico de depressão bem como das contingências ambientais que podem controlar padrões comportamentais depressivos, visando diminuir o autodenominar-se depressiva e estabelecer o entendimento de que seu caso não era de doença crônica. Paralelamente a isso, atuou-se em conjunto e sob orientação de um médico, no sentido de ir diminuindo a medicação antidepressiva.

\section{Resultado (item 4)}

A cliente deixou de atribuir alguns de seus comportamentos ao fato de "ter depressão", passando a discriminar quais contingências mantinham tais comportamentos problema, ou seja, passou a fazer análise funcional de seus comportamentos não precisando mais procurar causas fictícias fora de seu controle (a depressão).

Diminuiu, sensivelmente, os comportamentos queixosos em sessão e deixou de relatar situações cotidianas nas quais ficava se queixando ou falando com seus familiares sobre "sua depressão".

As informações sobre esse caso vão até o período em que o processo de seguimento terapêutico alcançou intervalos bimensais e, sob orientação médica, a dosagem de antidepressivo já havia sido reduzida a $25 \%$, caminhando para a redução total.

\section{DISCUSSÃO FINAL}

Imagino, o psicólogo à busca da normalidade, como o garimpeiro experiente à busca de pedras preciosas, isto é, o psicoterapeuta entrando, com poder, no contexto do dia-a-dia do cliente como um estímulo discriminativo para a normalidade (Sant'Anna, 1995, p. 7).

Ao não falar com alguém sobre seus problemas, a cliente isolou-se de sua comunidade verbal, e com isso, seu comportamento ficou sob o controle de regras idiossincráticas. Interagir com a terapeuta permitiu-lhe voltar ao controle por contingências, enfraquecendo a regra de que "sua vida era diferente ou anormal e que seu passado era terrível". Neste sentido, a terapeuta, como um influente membro de sua comunidade verbal, passou a fazer parte do contexto da cliente enquanto estímulo discriminativo para a normalidade. Ela passou a avaliar o seu passado como algo "normal". Em um exemplo, ela relatou ter contado pela primeira vez a mais alguém (a uma irmã) tudo o que lhe havia ocorrido, e esta reagiu também com naturalidade, contribuindo para o enfraquecimento dessas regras "disfuncionais". Como resultado da terapia, diminuiu sua ansiedade em relação ao passado e ela poderia, então, compartilhálo com membros de sua comunidade verbal sem medo de punição. A cliente relatou que fazer isto proporcionava-lhe uma sensação de liberdade.

A cliente passou a aceitar o passado como algo que poderia ser lembrado, porém, não alterado, o que, entretanto, não a impediria de ser feliz no presente. Concluiu que tudo o que fez no passado foi em decorrência do que um repertório de uma adolescente de 16 anos lhe permitia, dado aquele contexto. $\mathrm{O}$ controle da regra de que "seu passado poderia, ou deveria ter sido diferente" pareceu, desse modo, enfraquecido, o que permitiu uma mudança drástica no processo terapêutico. Livre dos comportamentos aversivos de sonhar e pensar e das regras "disfuncionais" em relação ao passado, a cliente pôde, afinal, entrar em contato com algumas de suas contingências de vida atuais: seu tratamento de depressão e suas relações familiares.

Quanto à depressão, constatou-se que, por um lado, a cliente respondia ao rótulo; ou seja, respondia à depressão como um fator interno que explicava seus problemas e, por outro lado, ainda recebia reforçadores sociais quando se queixava e manifestava sofrimento. A intervenção foi no sentido de enfraquecer o controle do rótulo e substituir os comportamentos "disfuncionais", depressivos ou não, pela construção de um repertório comportamental mais eficaz, principalmente, em autoconhecimento, em autogoverno e nas relações interpessoais.

A diminuição no controle do comportamento por regras "disfuncionais" permitiu à cliente ficar mais sensível às consequiências imediatas de seus comportamentos, podendo assim tratar dos seus 
problemas de relacionamento familiar no presente, identificar os mantenedores que estariam dificultando tais relacionamentos e, então, desenvolver formas mais apropriadas de interagir com o filho e com o marido. As mudanças acidentais nas contingências ambientais (quando a cliente permaneceu com o gesso) precipitaram mudanças de todos quanto à cooperação no trabalho; um processo provavelmente facilitado pela preparação anterior implementada pela terapeuta. Quando marido e filho passaram a trabalhar, a frequiência de situações reforçadoras positivas aumentou para todos. Além desses resultados referentes à qualidade das relações familiares, nas últimas sessões, a cliente relatou que até as relações sexuais com o marido, que antes eram ruins, haviam melhorado.

Pode-se afirmar que o comportamento da terapeuta, sem censura, parece ter favorecido a extinção de efeitos remanescentes das contingências punitivas do passado. A terapeuta, como uma diferente comunidade verbal (diferente daquela do passado) permitiu à cliente testar e reafirmar sua normalidade, superando o controle por regras "disfuncionais". Procedimentos fundamentados na análise do comportamento (com ênfase no modelo operante) e no behaviorismo radical propiciaram à cliente a construção de novos repertórios comportamentais, repertórios estes predominantemente sob o controle das contingências em vigor ou de regras mais apropriadas, os quais resultaram em maior autonomia e liberdade para a cliente viver seu futuro.

\section{REFERÊNCIAS}

Catania, A. C. (1999). Aprendizagem: Comportamento, linguagem e cognição (4. ed). Porto Alegre: ArtMed.

Gordon, S. B.; Keef, F. J. \& Kopel, S. A. (1980). Avaliação comportamental da discórdia conjugal. Em S. B. Gordon (Org.), Atualizações em terapia do comportamento: manual prático de avaliação comportamental (pp. 93-108). São Paulo: Manole.

Guilhard, H. J. (1998). Um modelo comportamental de análise de sonhos. Em: B. Rangé (Org.), Psicoterapia Comportamental e Cognitiva de Transtornos Psiquiátricos (pp. 257-267). Campinas: Editorial Psy.

Sant'Anna, R. C. (1995, setembro). Psicoterapia como estímulo discriminativo para a normalidade. Trabalho apresentado no IV Congresso da Associação Brasileira de Psicoterapia e Medicina Comportamental. Campinas.

Skinner, B. F. (1957). Verbal behavior. New York: Appleton-Century-Crofts.

Skinner, B. F. (1969). Contingencies of reiforcement. New York: Appleton-Century-Crofts.

Skinner, B. F. (1974). About behaviorism. New York: Knopf.

Skinner, B. F. (1998). Ciência e Comportamento Humano. São Paulo: Martins Fontes. (Originalmente publicado em 1953).

Ullmann, L. P. \& Krasner, L. (1975). A psychological approach to abnormal behavior (2. ed). New Jersey: Prentice-Hall. 


\section{Nota \\ ${ }^{1}$ Alguns dados biográficos da cliente foram alterados com o objetivo de impedir sua identificação.}

\section{Sobre as autoras}

Camila Muchon de Melo: Psicóloga; Mestranda em Filosofia e Metodologia das Ciências pela Universidade Federal de São Carlos - UFSCAR. Endereço eletrônico: camuchon@ hotmail.com.

Maura Alves Nunes Gongora: Professora da Universidade Estadual de Londrina; a) docente e supervisora no curso de graduação em Psicologia na área de Psicologia Clínica em Análise do Comportamento; b) docente no curso de especialização em "Psicoterapia na Análise do Comportamento" onde ministra a disciplina "Fundamentos do Behaviorismo Radical e Psicoterapia". Doutora em Psicologia Clínica (na Análise do Comportamento) pela USP; Pós-doutora em "Fundamentos do Behaviorismo Radical" na linha de pesquisa "Epistemologia e História da Psicologia", pelo departamento de "Filosofia e Metodologia das Ciências", da "Universidade Federal de São Carlos - UFSCAR"; c) Psicoterapeuta com experiência em atendimento clínico em consultório particular. 